\title{
Patient-Reported Outcomes in RA Patients Treated With Tofacitinib or bDMARDs in Real-life Conditions in Two Latin American Countries
}

JM Reyes ( $\sim$ JuanManuel.Reyes@pfizer.com )

Pfizer SAS

MV Gutierrez

Pfizer

H Madariaga

Centro Médico CEEN

W Otero

Centro Servimed

R Guzman

Centro IDEARG

$\mathrm{J}$ Izquierdo

Clínica del Occidente

M Abello

Centro Integral de Reumatología Circaribe

P Velez

Centro Médico CIREEM

D Castillo

Clínica del Occidente

Dario Ponce de Leon

Pfizer

T Lukic

Pfizer Inc

L Amador

Pfizer SAS

\section{Research Article}

Keywords: Patient Reported Outcome Measures, rheumatoid arthritis, tofacitinib, antirheumatic agents, Latin America

Posted Date: August 26th, 2021 
DOl: https://doi.org/10.21203/rs.3.rs-828468/v1

License: (c) (1) This work is licensed under a Creative Commons Attribution 4.0 International License. Read Full License 


\section{Abstract}

Objective: To describe the efficacy, safety and patient-reported outcomes (PROs) in patients with rheumatoid arthritis (RA) with an inadequate response to conventional synthetic disease-modifying antirheumatic drugs (csDMARDs) treated with tofacitinib or biological DMARDs (bDMARDs) in real-life conditions.

Methods: A noninterventional study was performed between March 2017 and September 2019 at 13 sites in Colombia and Peru. Demographic and clinical information was collected. Outcomes measured at baseline and at the 6-month follow-up were disease activity (RAPID3 [Routine Assessment of Patients Index Data] score), functional status (HAQ-DI [Health Assessment Questionnaire] score), and quality of life (EQ-5D-3L [EuroQol Questionnaire]). The Disease Activity Score-28 (DAS28-ESR) and frequency of adverse events (AEs) were also reported. Unadjusted and adjusted differences from baseline were estimated and expressed as the least squares mean difference (LMDs).

Results: Data from 100 patients treated with tofacitinib and 70 patients with bDMARDs were collected. At baseline, the patients' mean age was 53.53 years (SD 13.77), the mean disease duration was 6.31 years (SD 7.01) and the mean DAS28-ESR was 5.48 (SD 2.97). The change from baseline at month 6 was not statistically significant different in the adjusted LMD [SE] for tofacitinib vs. bDMARDs for RAPID3 score $(-0.20$ [0.69] vs. -0.32 [0.71]), HAQ-DI score (-0.56 [0.07] vs. -0.50 [0.08]), EQ-5D-3L score $(0.23$ [0.06] vs. 0.29 [0.06]) and DAS28-ESR (-3.86 [0.59] vs. -4.23 [0.61]). Patients from both groups presented similar proportions of nonserious and serious AEs. No deaths were reported. These results have noninterventional-study-specific limitations.

Conclusion: Changes from baseline were not statistically significant different between tofacitinib and bDMARDs in terms of RAPID3 scores and the secondary outcomes (HAQ-DI score, EQ-5D-3L score and DAS28-ESR). Patients from both groups presented similar proportions of nonserious and serious AEs.

\section{Clinical trial number: NCT03073109}

\section{Key Summary Points}

- There is limited information on the use of tofacitinib in current practice in Latin America, including studies comparing tofacitinib with bDMARDs directly in a real-world Latin American setting.

- This study attempt to describe the related physical activity, disease activity, quality of life and safety in Latin American patients with RA treated with tofacitinib or bDMARDs after the failure of csDMARDs in real-life conditions.

- This is the first study that evaluated PROs in RA patients from two Latin American countries and provides information related to the effectiveness of tofacitinib or biologic DMARDs in a real-world setting. 
- Similar baseline changes were seen at month 6 in outcomes such as disease activity, functional status, and quality of life measured through PROs for tofacitinib or bDMARDs each given in combination with CDMARDs in RA patients with moderate to severe diseases who were nonresponders to cDMARDs in a real-world setting.

\section{Background}

Rheumatoid arthritis (RA) is an autoimmune, chronic, systemic disorder that affects approximately $1 \%$ of the world's population (1). RA is characterized by synovial membrane swelling and causes joint swelling, stiffness and pain, which lead to cartilage and bone tissue progressive erosion and destruction at the affected joints. Between $17.85 \%$ and $40.90 \%$ of patients with RA may experience extra-articular manifestations that may involve skin, eye, respiratory, oral, cardiovascular, neurological, hematological or vascular function (2-5). Patients with RA are also likely to experience depression, sexual dysfunction, and social relationship disruption $(6,7)$.

Furthermore, RA represents an important burden for informal caregivers (spouse, relatives) who spend much time helping patients with their daily activities, personal care, social activities and financial matters $(8,9)$. This caregiver overload contributes substantially to a loss of productivity and the total disease burden.

For patients, RA remains an incurable disease; thus, the treatment goals are to relieve disease signs and symptoms, control disease activity, improve physical function and patient quality of life and inhibit structural damage progression in the disease course (10-12).

There are effective therapies for RA. Commonly, patients initiate nonsteroidal anti-inflammatory drugs (NSAIDs) or low-dose glucocorticoids and conventional synthetic disease-modifying anti-rheumatic drugs (csDMARDs) as soon as possible after diagnosis. Biological disease-modifying anti-rheumatic drugs (bDMARDs) and targeted synthetic disease-modifying anti-rheumatic drugs (tsDMARDs), such as tofacitinib, are drugs used for preventing or reducing the swelling caused by RA after the failure of csDMARDs (2-5).

Currently, tofacitinib $5 \mathrm{mg}$ twice daily (BID) (approved dosage for treatment of RA) has demonstrated consistent efficacy in reducing the signs and symptoms of RA and has led to improvements in patientreported outcomes (PROs), with manageable safety profiles across six phase III studies and one phase IV study in different stages of arthritis, either as monotherapy or in combination with csDMARDs (13-18). Tofacitinib has demonstrated a consistent safety profile in open-label long-term extension clinical studies (19).

There is limited information on the use of tofacitinib in current practice in Latin America (20), including studies comparing tofacitinib with bDMARDs directly in a real-world Latin American setting. Due to the great importance of the studies that are focusing on comparisons of broad types of treatments in the management of RA patients in current clinical practice, we aimed to describe the related physical activity, 
disease activity, quality of life and safety in Latin American patients with RA treated with tofacitinib or bDMARDs after the failure of csDMARDs in real-life conditions.

\section{Methods}

\section{Setting and population}

A noninterventional, hybrid study (retrospective and prospective study) with two arms comparing tofacitinib to bDMARDs treatments in patients with RA after the failure of csDMARDs was performed from March 2017 through September 2019. The retrospective period corresponds to the time from when the physician prescribed the studied drug until the patient decided to participate in the study, while the prospective period is the period from recruitment until six months of follow-up. This study was conducted in 13 sites from Colombia and Peru. Patients were followed up for 6 months and were in primary care. Changes to the treatment and use of concomitant medications during the follow-up were within current practice guidelines and were decided upon by their rheumatologist under real-world conditions. The protocol was approved by the Independent Ethics Committee at each center. All the patients provided written informed consent. Clinical trial number: NCT03073109

The patients were $\geq 18$ years of age, had been diagnosed with moderate to severe RA for more than 6 months before enrollment, had a Disease Activity Score 28-joint based on erythrocyte sedimentation rate (DAS28-ESR) score $\geq 3.2$, with inadequate response to the continuous use of methotrexate or combination of csDMARDs for at least 12 weeks before the study entry, with no previous bDMARDs use, and had been prescribed tofacitinib or bDMARDs in the last three weeks at doses established by the American College of Rheumatology (ACR) guidelines published in 2015 and following medical criteria. The definition of RA diagnosis was based on the criteria used in medical practice for each rheumatologist.

The exclusion criteria were patients who were not able to answer the questionnaires; patients diagnosed with autoimmune rheumatic diseases other than RA and Sjogren's syndrome; patients treated with bDMARDs as monotherapy; patients who had participated in other studies; pregnant or breastfeeding women; and patients with any current malignancy or history of malignancy with the exception of adequately treated or excised nonmetastatic basal cell or squamous cell cancer of the skin or cervical carcinoma in situ, lymphoproliferative disorders, a history of lymphoma, leukemia, or signs and symptoms suggestive of current lymphatic disease.

\section{Sampling strategy}

Sample size was estimated based on the primary objective to compare the disease activity between both groups as measured by the Routine Assessment of Patient Index Data 3 (RAPID3). Taking into account the results obtained in prior studies with bDMARDs, a difference of 2 points in the RAPID3, with a standard deviation (SD) of 6 in both arms, a confidence level of $95 \%$ and a statistical power of $80 \%$, 
approximately 142 patients were required in each arm. With a correction factor of $15 \%$ considering the proportion of patients who could drop out during the study, the minimum number of patients required was approximately 160 per arm. Sampling was conducted at the main sites using tofacitinib in the participating countries. Convenience sampling was conducted in the tofacitinib group due to the limited number of patients, while the patients treated with bDMARDs were collected randomly with replacement through numbers generated by computer delivery.

\section{Outcome measures}

All the outcomes defined in the study were measured through PROs at month 0 and at month 6 through questionnaires completed by the patients. The scales used had been previously validated in the Spanish language and registered the information reported in the medical records. The primary assessed outcome was disease activity, which was measured through the RAPID3. The other involved outcomes were functional status, which was measured through the adapted Health Assessment Questionnaire Disability Index (adapted HAQ-DI) and quality of life, which was measured with the EuroQoL 5-Dimension 3-Level (EQ-5D-3L). The only outcome measure that was extracted from the medical records was the Disease Activity Score 28-joint count assessment-erythrocyte sedimentation rate (DAS28-ESR) because it is routinely used in clinical practice.

Adverse event $(\mathrm{AE})$ frequency and severity occurring due to the prescription of therapies under evaluation were assessed after 6 months of follow-up. AE frequency and severity were measured from the information on the medical record or were spontaneously reported by the patients during the medical visit.

Other data related to the patient's demographic and clinical characteristics, treatment details and limitations in the health care system were abstracted from the medical records to describe the population and possible potential confounders.

\section{Statistical analysis}

Matched analysis was planned through propensity score matching; however, the achieved number of recruited patients did not allow propensity score matching. Descriptive statistics were produced for all variables. These included estimates of the mean, standard deviation, $95 \%$ confidence intervals of the mean, median, interquartile ranges and frequency distributions for continuous-scale variables and frequency distributions for categorical-scale variables.

Functional status (adapted HAQ-DI), quality of life (EQ-5D-3L) and disease activity (RAPID3 and DAS28ESR) were analyzed by directly estimating the difference in means using least square means (LSM) between patients treated with tofacitinib and patients treated with bDMARDs and between periods. A bivariate and multivariable analysis was performed to identify the association between the baseline variables and the disease activity. These analyses were conducted considering demographic and clinical characteristics, concomitant treatment, previous treatment and access variables when the $p$ value was less than 0.05 . 


\section{Results}

\section{Characteristics of the participants and study completion}

During the study period, 170 patients were enrolled in the study, including 100 patients treated with tofacitinib and 70 treated with bDMARDs ( $85 \%$ treated with etanercept, rituximab, tocilizumab and infliximab). Eighty-six patients were from Colombia, and 83 patients were from Peru. At the 6-month follow-up, $92.9 \%$ (158) of enrolled patients completed the study, including 90 in the tofacitinib group and 68 in the bDMARDs group. Nine patients withdrew due to a loss to follow-up (tofacitinib $(n=8)$ and bDMARDs $(n=1)) ; 2$ patients treated with tofacitinib discontinued for other reasons. Only 1 patient from the bDMARDs group discontinued the study due to AEs. Although the mean time to supply at the start of the treatment was similar in both groups, more dispersion was observed in patients who received tofacitinib.

The mean age was 53.53 years (25th-75th percentile $42.66-64.44$ ); $88 \%$ were women, and $97 \%$ were living in urban areas. The mean disease duration was 6.31 (25th-75th percentile 2.00-9.00) years. Methotrexate $(58.82 \%)$, leflunomide $(19.41 \%)$, or any chloroquine $(11.76 \%)$ were the most frequent csDMARDs previously used. Corticosteroids were used previously in $82.94 \%$ of patients.

When comparing baseline data, the main differences were found in insurance characteristics and previous treatments. Patients had mainly private health insurance $(n=91)$, followed by public health insurance $(n=53)$. More patients with tofacitinib had coverage through private health insurance $(67 \%)$, while the majority of the bDMARDs group had coverage through public health insurance (59\%). The group that received tofacitinib reported more access limitation than patients with bDMARDs ( $29 \%$ vs $14 \%)$. Another observed difference in both studied groups was in the proportions of patients with concomitant treatment with leflunomide, previous use of methotrexate, and previous use of prednisolone. Although the mean time to supply to start the treatment was similar in both groups, more dispersion was reported in patients who received tofacitinib (Table 1). 
Table 1

Demographic and clinical characteristics of patients by groups

\begin{tabular}{|c|c|c|c|}
\hline & bDMARDs group & Tofacitinib group & p-value \\
\hline Number of subjects & 70 & 100 & \\
\hline Age mean (SD) & $51(13)$ & $55(14)$ & 0.072 \\
\hline Female - No. of patients & $65(93 \%)$ & $85(85 \%)$ & 0.11 \\
\hline \multicolumn{4}{|l|}{ Country - No. of patients } \\
\hline Peru & $45(64 \%)$ & $39(39 \%)$ & 0.002 \\
\hline Colombia & $25(36 \%)$ & $61(61 \%)$ & \\
\hline \multicolumn{4}{|l|}{ Area - No. of patients } \\
\hline Rural & $1(1.4 \%)$ & $5(5 \%)$ & 0.41 \\
\hline Urban & $69(99 \%)$ & $95(95 \%)$ & \\
\hline \multicolumn{4}{|l|}{ Access information } \\
\hline \multicolumn{4}{|l|}{ Access mechanism - No. of patients } \\
\hline Complementary & $1(1.4 \%)$ & $2(2 \%)$ & $<0.001$ \\
\hline Patient & $1(1.4 \%)$ & $10(10 \%)$ & \\
\hline Private & $24(34 \%)$ & $67(67 \%)$ & \\
\hline Public & $41(59 \%)$ & $12(12 \%)$ & \\
\hline No report & $3(4.3 \%)$ & $9(9 \%)$ & \\
\hline Access limitation - No. of patients & $10(14 \%)$ & $29(29 \%)$ & 0.024 \\
\hline No report & $3(4.3 \%)$ & $9(9 \%)$ & \\
\hline Time to supply (days) mean (SD) & $24(31)$ & $22(45)$ & 0.0017 \\
\hline Disease year mean (SD) & $6(6.8)$ & $6.5(7.2)$ & 0.81 \\
\hline Time previous treatment mean (SD) & $34(37)$ & $26(31)$ & 0.091 \\
\hline \multicolumn{4}{|c|}{ Concomitant therapy - No. of patients (\%) } \\
\hline Leflunomide - No. of patients & $20(29 \%)$ & $15(15 \%)$ & 0.05 \\
\hline Methotrexate - No. of patients & $30(56 \%)$ & $52(52 \%)$ & 0.75 \\
\hline Aminoquinolines - No. of patients & $7(10 \%)$ & $16(16 \%)$ & 0.37 \\
\hline
\end{tabular}

bDMARDs: biological disease-modifying anti-rheumatic drugs; SD: standard deviation 


\begin{tabular}{|llll|}
\hline & bDMARDs group & Tofacitinib group & p-value \\
\hline Corticosteroids - No. of patients & $60(86 \%)$ & $77(77 \%)$ & 0.22 \\
\hline Clinical characteristics & & & \\
\hline Lymphocytes $/ \mathrm{mm}^{3}$ mean (SD) & $2,200(865)$ & $2,600(1,800)$ & 0.71 \\
\hline Neutrophils/mm ${ }^{3}$ mean (SD) & $4,400(2,500)$ & $4,600(2,200)$ & 0.58 \\
\hline Swollen joins mean (SD) & $6.9(4.2)$ & $8.7(7.2)$ & 0.18 \\
\hline Tender joints mean (SD) & $10(4.4)$ & $11(7.3)$ & 0.57 \\
\hline Medical condition & $1.4 \%(1)$ & $7(7 \%)$ & 0.18 \\
\hline DAS28-ESR mean (SD) & $5.9(4.5)$ & $5.2(1)$ & 0.28 \\
\hline Previous treatment - No. of patients (\%) & & & 0.19 \\
\hline Deflazacort - No. of patients & $9(13 \%)$ & $22(22 \%)$ & 0.78 \\
\hline Leflunomide - No. of patients & $11(16 \%)$ & $13(13 \%)$ & 0.0055 \\
\hline Methotrexate & $18(26 \%)$ & $48(48 \%)$ & 0.015 \\
\hline Prednisolone - No. of patients & $40(57 \%)$ & $37(37 \%)$ & 1 \\
\hline Folic acid - No. of patients & $0(0 \%)$ & $1(1 \%)$ & 0.79 \\
\hline Chloroquine - No. of patients & $4(5.7 \%)$ & $8(8 \%)$ & 1 \\
\hline Hydroxychloroquine - No. of patients & $2(2.9 \%)$ & $2(3 \%)$ & 0.33 \\
\hline Sulfasalazine & $2(2.9 \%)$ & $0(0 \%)$ & $1(1 \%)$ \\
\hline Methylprednisolone & $1(1.4 \%)$ & & 1 \\
\hline bDMARDs: biological disease-modifying anti-rheumatic drugs; SD: standard deviation & \\
\hline & & & \\
\hline
\end{tabular}

The patients had severe disease activity according to the DAS28-ESR reported at baseline, 5.9 (SD 4.5) for bDMARDs and 5.2 (SD 1) for tofacitinib. Seven percent of patients prescribed tofacitinib had any comorbidity, whereas this value was $1.4 \%$ for the bDMARDs group. Lymphocyte counts, neutrophil counts, and the numbers of swollen joints and tender joints were similar between the study groups.

\section{PRO results}

The measurement of outcomes (RAPID3, adapted HAQ-DI, EQ5D) was conducted at baseline in 100 patients in the tofacitinib group and in 70 patients in the bDMARDs group. Ninety and sixty-eighty patients in the tofacitinib and bDMARDs groups, respectively, completed the study and had RAPID3, adapted HAQ-DI and EQ5D scores recorded at the last visit. The DAS28-ESR is another response measure 
of disease activity, and the availability of data depends on its use in clinical practice. DAS28-ESR data were available for all patients at baseline; however, at the second visit, DAS28-ESR data were reported in only 86 patients treated with tofacitinib and 61 treated with bDMARDs.

Regarding the primary outcome of this study, RAPID3 scores changed from baseline to month 6 , and there was a reduction in the mean score during the follow-up period for both studied treatments ( $p$ value $>0.001$ ) (Fig. 1). At the end of follow-up, a similar proportion of patients treated with tofacitinib and bDMARDs achieved remission, while 18\% more patients from the bDMARDs group than the tofacitinib group achieved low disease activity (Fig. 2). The reduction in RAPID3 score was similar between the bDMARDs and tofacitinib groups, but the difference was not statistically significant ( $p$ value 0.154 ) (Table 2). After adjusting for covariables (access limitation, tofacitinib interruption, previous use of methotrexate and complementary access mechanism), the same tendency remained.

Table 2

PRO mean changes from baseline to month 6 in bivariable analyses by groups

\begin{tabular}{|lcl|}
\hline & bDMARDs group & Tofacitinib group \\
\hline RAPID3 & $-3.28 \pm 0.30$ & $-2.71 \pm 0.26$ \\
\hline Adapted HAQ-DI & $-0.68 \pm 0.08$ & $-0.66 \pm 0.07$ \\
\hline EQ-5D-3L & $0.43 \pm 0.05$ & $0.35 \pm 0.04$ \\
\hline DAS28-ESR & $-3.03 \pm 0.42$ & $-2.13 \pm 0.35$ \\
\hline $\begin{array}{l}\text { Values are the mean } \pm \text { SE. bDMARDs: biological disease-modifying anti-rheumatic drugs DAS28-ESR: } \\
\text { Disease Activity Score 28-joint count assessment-erythrocyte sedimentation rate; HAQ-DI: Health } \\
\text { Assessment Questionnaire - Disability Index; EQ-5D-3L: EuroQoL 5-Dimension 3-Level; PRO: } \\
\text { reported outcomes; RAPID3: Routine Assessment of Patient Index Data 3; SE: standard error. }\end{array}$ \\
\hline
\end{tabular}

Pain and health status are other dimensions included in the RAPID3. Patients who received tofacitinib reported a mean reduction in pain of $3.94 \pm 0.89$, while bDMARDs patients reported a mean reduction of $3.28 \pm 0.77$. In the health status dimension, the tofacitinib group presented an improvement of $3.79 \pm$ 0.47 , whereas the bDMARDs group presented an improvement of $2.78 \pm 0.47$. Differences in both groups for these outcomes were not found ( $p$ value 0.577 and 0.104 ).

Likewise, the reduction in the disease activity as measured using the DAS28-ESR for both groups was statistically significant comparing baseline and month 6 ( $p$ value $<0.001$ ) (Fig. 1). During the follow-up period, the tendency of baseline change in the DAS28-ESR was similar for the tofacitinib and bDMARDs groups in both bivariable and multivariate analyses ( $p$ value $=0.098$ and 0.484 , respectively) (Table 2). The proportion of patients who achieved remission at month 6 was almost twice that observed with the RAPID3 and similar in both studied groups. For low disease activity, $11 \%$ more bDMARDs patients than tofacitinib patients reported low disease activity (Fig. 2). 
Regarding other secondary PROs, patients who received tofacitinib or bDMARDs reported an improvement in their functional status and quality of life, with no statistically significant difference between groups in the mean change during the follow-up period ( $p$ value: 0.838 and 0.170 , respectively) (Table 2). Comparable results were obtained when other covariables were controlled for in the multivariable analysis ( $p$ value: 0.571 and 0.388 for the tofacitinib group and bDMARDs group, respectively).

\section{Safety}

Twenty patients treated with tofacitinib and sixteen treated with bDMARDs reported any AEs. The most frequent events (over $2 \%$ ) in patients treated with bDMARDs were diarrhea, pharyngitis, falls, headache, urinary tract infection, and nasopharyngitis, while those for tofacitinib group were headache, influenza, and pharyngotonsillitis. Herpes simplex and herpes zoster were reported in 2 patients treated with tofacitinib (Table 3).Cardiovascular, malignancies or thromboembolism AEs were not reported. Two serious AEs were reported by one patient treated with tofacitinib (appendicitis and peritonitis that were reported as not related to the treatment) 
Table 3

Adverse events reported by groups

\begin{tabular}{|c|c|c|c|c|}
\hline & \multicolumn{2}{|c|}{$\begin{array}{l}\text { Tofacitinib } \\
\text { group }\end{array}$} & \multicolumn{2}{|c|}{$\begin{array}{l}\text { bDMARDs } \\
\text { group }\end{array}$} \\
\hline & $\mathrm{n}$ & $(\%)$ & $\mathrm{n}$ & $(\%)$ \\
\hline Patients evaluable for adverse events & 100 & & 70 & \\
\hline Number of subjects with serious adverse events & 1 & $(1.00)$ & 0 & $(0.00)$ \\
\hline Number of subjects with non-serious adverse events & 20 & $(20.00)$ & 16 & $(22.86)$ \\
\hline Number of non-serious adverse events & 30 & $(30.00)$ & 20 & $(28.57)$ \\
\hline Number (\%) of subjects with one (1) adverse event & 12 & $(60.00)$ & 12 & $(75.14)$ \\
\hline Number (\%) of subjects with two (2) adverse events: & 6 & $(30.00)$ & 4 & $(5.71)$ \\
\hline Number of subjects with three (3) adverse events & 2 & $(10.00)$ & 0 & $(0.00)$ \\
\hline \multicolumn{5}{|c|}{$\begin{array}{l}\text { Non serious adverse events according to System Organ Classes } \\
\text { (SOC) }\end{array}$} \\
\hline Blood and lymphatic system disorders & 2 & $(2.00)$ & 1 & $(1.43)$ \\
\hline Bicytopenia & 1 & $(1.00)$ & 0 & $(0.00)$ \\
\hline Neutropenia & 0 & $(0.00)$ & 1 & $(1.43)$ \\
\hline Purpura & 1 & $(1.00)$ & 0 & $(0.00)$ \\
\hline Endocrine disorders & 1 & $(1.00)$ & 0 & $(0.00)$ \\
\hline Oligomenorrhea & 1 & $(1.00)$ & 0 & $(0.00)$ \\
\hline Eye disorders & 2 & $(2.00)$ & 0 & $(0.00)$ \\
\hline Photophobia & 1 & $(1.00)$ & 0 & $(0.00)$ \\
\hline Vision blurred & 1 & $(1.00)$ & 0 & $(0.00)$ \\
\hline Gastrointestinal disorders & 1 & $(1.00)$ & 4 & $(5.71)$ \\
\hline Abdominal pain & 0 & $(0.00)$ & 1 & $(1.43)$ \\
\hline Diarrhea & 1 & $(1.00)$ & 3 & $(4.29)$ \\
\hline General disorders and administration site conditions & 1 & $(1.00)$ & 0 & $(0.00)$ \\
\hline Malaise & 1 & $(1.00)$ & 0 & $(0.00)$ \\
\hline Infections and infestations & 2 & $(2.00)$ & 0 & $(0.00)$ \\
\hline Herpes simplex & 1 & $(1.00)$ & 0 & $(0.00)$ \\
\hline Herpes zoster & 1 & $(1.00)$ & 0 & $(0.00)$ \\
\hline
\end{tabular}




\begin{tabular}{|c|c|c|c|c|}
\hline \multirow[b]{2}{*}{ Injury, poisoning and procedural complications } & \multicolumn{2}{|c|}{$\begin{array}{l}\text { Tofacitinib } \\
\text { group }\end{array}$} & \multicolumn{2}{|c|}{$\begin{array}{l}\text { bDMARDs } \\
\text { group }\end{array}$} \\
\hline & 0 & $(0.00)$ & 2 & $(2.86)$ \\
\hline Fall & 0 & $(0.00)$ & 2 & $(2.86)$ \\
\hline Musculoskeletal and connective tissue disorders & 3 & $(3.00)$ & 2 & $(2.86)$ \\
\hline Arthralgia & 1 & $(1.00)$ & 0 & $(0.00)$ \\
\hline Coccydynia & 0 & $(0.00)$ & 1 & $(1.43)$ \\
\hline Lumbar vertebral fracture & 1 & $(1.00)$ & 0 & $(0.00)$ \\
\hline Musculoskeletal pain & 0 & $(0.00)$ & 1 & $(1.43)$ \\
\hline Myalgia & 1 & $(1.00)$ & 0 & $(0.00)$ \\
\hline Nervous system disorders & 4 & $(4.00)$ & 2 & $(2.86)$ \\
\hline Headache & 3 & $(3.00)$ & 2 & $(2.86)$ \\
\hline Spinal pain & 1 & $(1.00)$ & 0 & $(0.00)$ \\
\hline Renal and urinary disorders & 3 & $(3.00)$ & 2 & $(2.86)$ \\
\hline Cystitis & 1 & $(1.00)$ & 0 & $(0.00)$ \\
\hline Pollakiuria & 1 & $(1.00)$ & 0 & $(0.00)$ \\
\hline Urinary tract infection & 1 & $(1.00)$ & 2 & $(2.86)$ \\
\hline Reproductive system and breast disorders & 1 & $(1.00)$ & 0 & $(0.00)$ \\
\hline Vulvovaginitis & 1 & $(1.00)$ & 0 & $(0.00)$ \\
\hline Respiratory, thoracic and mediastinal disorders & 8 & $(8.00)$ & 7 & $(10,0)$ \\
\hline Cough & 1 & $(1.00)$ & 0 & $(0.00)$ \\
\hline Influenza & 3 & $(3.00)$ & 1 & $(1.43)$ \\
\hline Nasopharyngitis & 0 & $(0.00)$ & 2 & $(2.86)$ \\
\hline Pharyngitis & 1 & $(1.00)$ & 3 & $(4.29)$ \\
\hline Pharyngitis bacterial & 1 & $(1.00)$ & 0 & $(0.00)$ \\
\hline Pharyngotonsillitis & 2 & $(2.00)$ & 0 & $(0.00)$ \\
\hline Rhinorrhea & 0 & $(0.00)$ & 1 & $(1.43)$ \\
\hline Skin and subcutaneous tissue disorders & 2 & $(2.00)$ & 0 & $(0.00)$ \\
\hline Alopecia & 1 & $(1.00)$ & 0 & $(0.00)$ \\
\hline
\end{tabular}




\begin{tabular}{|lllll|}
\hline & \multicolumn{2}{l}{$\begin{array}{l}\text { Tofacitinib } \\
\text { group }\end{array}$} & \multicolumn{2}{l|}{$\begin{array}{l}\text { bDMARDs } \\
\text { group }\end{array}$} \\
\hline Ecchymosis & 1 & $(1.00)$ & 0 & $(0.00)$ \\
\hline
\end{tabular}

\section{Discussion}

This is the first study that evaluated PROs in RA patients from two Latin American countries and provided information related to the effectiveness of tofacitinib or biologic DMARDs. The results suggest similar baseline changes at month 6 in the measured PROs for tofacitinib or bDMARDs, each given in combination with csDMARDs, in RA patients with moderate to severe diseases who were nonresponders to csDMARDs. Both treatments achieved comparable changes in the score for the primary outcome, RAPID3 score. Likewise, the magnitude of the response in the other PROs and outcome measures were similar for both treatment groups, including disease activity, functional status, and quality of life. However, these results should be interpreted with caution given the study design and sample size. The rates of $A E$ were balanced for both tofacitinib and bDMARDs.

The results are consistent with those observed in a clinical trial that compared tofacitinib monotherapy versus tofacitinib or adalimumab combined with methotrexate in patients with rheumatoid arthritis with inadequate response to methotrexate. The HAQ-DI score and pain as PROs were assessed. The results of changes from baseline at 6 months showed comparable results for tofacitinib and adalimumab in combination with methotrexate for both self-report questionnaires (21).

Although the RAPID3 is not commonly used in clinical trials, it has been widely studied. One study found an association between this PRO and quality of life, explaining $81 \%$ of the variability in the RAPID3 (22). This finding is consistent with the results of this study, where the changes from baseline were similar between the RAPID3 and the EQ5D-3L.

Studies have reported a correlation between the RAPID3 and the DAS28-ESR of 0.62 and 0.71 , which is considered moderate $(23,24)$. In contrast to the DAS28-ESR, the RAPID3 includes pain as one domain of the scale being a main factor, which has been considered by patients as a relevant outcome as well as quality of life and the erosion of imagen (25). However, the DAS28-ESR remains the main established composite measure of disease activity to measure disease activity in clinical trials. The results in this study showed similar changes from baseline to month 6 for RAPID3 scores and DAS28-ESR in both studied groups, but in the classification of the diseases, changes in disease activity fluctuated, with a higher percentage of patients in remission or with low disease activity according to the DAS28-ESR.

Despite our study not showing a difference between tofacitinib and biologics and there were no cases of MACE, malignancies or thrombosis reported, a recently completed Phase 3b/4 randomized, open-label safety study found that the non-inferiority criterion was not met comparing the tofacitinib doses combined (5mg BID and 10mg BID) vs TNFi for the co-primary endpoints of adjudicated MACE and malignancies excluding NMSC (26). Also, previously reported data from an ad hoc safety analysis of the 
same study showed an increased risk of venous thromboembolic events for tofacitinib relative to TNFi (27).

Tofacitinib is associated with an increased risk of herpes zoster compared with bDMARDs (28). This study reported one case of simple herpes zoster and another of herpes simplex in patients treated with tofacitinib, with an incidence similar to that in an extended study of 9.5 years of use of tofacitinib, which reported an incidence of 2.7 per 100 patients per year (29).

The study has some limitations. The target sample size was not met, affecting the power of the study and limiting the conclusions of the study. Patients selected for enrollment in the study represented a "convenience sample", ensuring that the records were obtained from physicians willing to be involved in the study. Thus, the results of the study may not be applicable to the general RA population or to physicians treating RA in the countries included, and the characteristics of the patients who agreed to participate in the study could be different from those of the population of the study. There was heterogeneity among patients, which was controlled by multivariable analysis; however, this was limited to observable covariables, and some of these variables could be distributed differently between groups.

The results of this study can be generalized to other Latin American countries with health care systems and access limitations to the treatment similar to those of the countries of this study. Additionally, the results can be applied only for patients with RA with a failure of csDMARDs or with treatment in combination with any csDMARDs.

The study has also strengths. There were specific criteria in the selection of sites ensuring the quality of data in the medical records. Additionally, despite the limitations of studies in real-world settings, this study used validated composite measures of disease activity and PROs without any influence from physicians due to the design of outcome measures and PROs, as per current clinical practice. Although the sample size achieved was lower than planned, most of the patients came from several sites in Colombia and Peru that were more representative of the different management of RA. Last, there was not high heterogeneity between study groups in the measured variables, increasing the validity of the results.

In conclusion, in patients diagnosed with RA and inadequate response to csDMARDs, tofacitinib and bDMARDs combined with csDMARDs demonstrated similar clinical results in outcome measures and PROs, as well as frequencies of AEs. Further studies are necessary to confirm these results.

\section{Abbreviations}

ACR: American College of Rheumatology

Adapted HAQ-DI: adapted Health Assessment Questionnaire - Disability Index

AE: Adverse event

bDMARDs: Biological disease-modifying anti-rheumatic drugs 
BID: twice daily

csDMARDs: conventional synthetic disease-modifying antirheumatic drugs

DAS28-ESR: Disease Activity Score 28-joint based on erythrocyte sedimentation rate

EQ-5D-3L: EuroQoL 5-Dimension 3-Level

LSM: Least square means

NSAIDs: nonsteroidal anti-inflammatory drugs

PROs: Patient-reported outcomes

RA: Rheumatoid arthritis

RAPID3: Routine Assessment of Patient Index Data 3

tsDMARDs: targeted synthetic disease-modifying anti-rheumatic drugs

\section{Declarations}

\section{Ethics approval and consent to participate:}

The protocol and that informed consent has been obtained from the subjects were approved by the Independent Ethics Committee at each center. The study was conducted in accordance with the Declaration of Helsinki and the local regulation of the participant countries.

\section{Consent for publication:}

Not applicable

\section{Availability of data and materials:}

The datasets used and/or analyzed during the current study are available from the corresponding author on reasonable request.

\section{Competing interests:}

Reyes JM, Gutierrez MV, Ponce de Leon D, Lukic T, and Amador L are employees of Pfizer. Del Castillo D and Izquierdo $\mathrm{J}$ have received speakers fees from several pharmaceutical companies.

\section{Funding:}

This work was funded by Pfizer Inc

\section{Author contributions:}


All authors contributed to the study conception and design. Material preparation was performed by JMR, MG, DPL and TL. The data collection was conducted by the different site participants. The analysis was executed by JMR and MG, and reviewed by all the authors. The first draft of the manuscript was written by JMR and all authors commented on previous versions of the manuscript. All authors read and approved the final manuscript.

\section{Acknowledgment:}

We thank all the following Research Centers for allowing us to conduct the study from 2017 to 2019: Centro Integral de Reumatología del Caribe Circaribe, SERVIMED, Centro de Investigaciones en Reumatología y Especialidades Médicas SAS, Reumalab, Fundación Valle de Lili, Clínica Jockey Salud, Clínica San Judas Tadeo, Clínicos IPS, Centro Medico CEEN, Fundación Instituto de Reumatología Fernando Chalem, Clínica de Occidente, Artmedica and IDEARG and all the investigators who contributed their knowledge, expertise and the integrity of the work as a whole. Likewise, we thank all the patients that accepted to participate in the study.

\section{References}

1. Schurgers E, Billiau A, Matthys P. Collagen-Induced Arthritis as an Animal Model for Rheumatoid Arthritis: Focus on Interferon-g.

2. Myasoedova E, Crowson CS, Kremers HM, Therneau TM, Gabriel SE. Is the incidence of rheumatoid arthritis rising?: Results from Olmsted County, Minnesota, 1955-2007. Arthritis Rheum. 2010 Feb 26;62(6):1576-82.

3. Helmick CG, Felson DT, Lawrence RC, Gabriel S, Hirsch R, Kwoh CK, et al. Estimates of the prevalence of arthritis and other rheumatic conditions in the United States. Part I. Arthritis Rheum. 2008 Jan;58(1):15-25.

4. Aletaha D, Neogi T, Silman AJ, Funovits J, Felson DT, Bingham CO, et al. 2010 Rheumatoid arthritis classification criteria: an American College of Rheumatology/European League Against Rheumatism collaborative initiative. Arthritis Rheum. 2010 Sep;62(9):2569-81.

5. Prete M, Racanelli V, Digiglio L, Vacca A, Dammacco F, Perosa F. Extra-articular manifestations of rheumatoid arthritis: An update. Autoimmun Rev. 2011 Dec;11(2):123-31.

6. Dickens C. The burden of depression in patients with rheumatoid arthritis. Rheumatology. 2001 Dec;40(12):1327-30.

7. El Miedany Y, El Gaafary M, El Aroussy N, Youssef S, Ahmed I. Sexual dysfunction in rheumatoid arthritis patients: arthritis and beyond.

8. Jacobi CE, van den Berg B, Boshuizen HC, Rupp I, Dinant HJ, van den Bos GAM. Dimension-specific burden of caregiving among partners of rheumatoid arthritis patients. Rheumatology (Oxford). 2003 Oct;42(10):1226-33. 
9. Brouwer WBF, van Exel NJA, van de Berg B, Dinant HJ, Koopmanschap MA, van den Bos GAM. Burden of caregiving: evidence of objective burden, subjective burden, and quality of life impacts on informal caregivers of patients with rheumatoid arthritis. Arthritis Rheum. 2004 Aug;51(4):570-7.

10. Smolen J, Ledenwé R, Breedveld F. EULAR recommendations for the management of rheumatoid arthritis with synthetic and biological disease-modifying antirheumatic drugs. Ann Rheum Dis. 2010;69:964-975.

11. Singh JA, Furst DE, Bharat A, Curtis JR, Kavanaugh AF, Kremer JM, et al. 2012 update of the 2008 American College of Rheumatology recommendations for the use of disease-modifying antirheumatic drugs and biologic agents in the treatment of rheumatoid arthritis. Arthritis Care Res (Hoboken). 2012 May;64(5):625-39.

12. Ruffing V, Bingham C. Rheumatoid arthritis: Treatment. The Jhons Hopkins Arthritis Center. 2013.

13. van Vollenhoven RF, Fleischmann R, Cohen S, Lee EB, García Meijide J a, Wagner S, et al. Tofacitinib or adalimumab versus placebo in rheumatoid arthritis. N Engl J Med. 2012 Aug 9;367(6):508-19.

14. Burmester GR, Blanco R, Charles-Schoeman C, Wollenhaupt J, Zerbini C, Benda B, et al. Tofacitinib $(\mathrm{CP}-690,550)$ in combination with methotrexate in patients with active rheumatoid arthritis with an inadequate response to tumour necrosis factor inhibitors: a randomised phase 3 trial. Lancet. 2013 Feb 9;381(9865):451-60.

15. van der Heijde D, Tanaka Y, Fleischmann R, Keystone E, Kremer J, Zerbini C, et al. Tofacitinib (CP$690,550)$ in patients with rheumatoid arthritis receiving methotrexate: Twelve-month data from a twenty-four-month phase III randomized radiographic study. Arthritis Rheum. 2013 Mar;65(3):55970.

16. Kremer J, Li Z-G, Hall S, Fleischmann R, Genovese M, Martin-Mola E, et al. Tofacitinib in combination with nonbiologic disease-modifying antirheumatic drugs in patients with active rheumatoid arthritis: a randomized trial. Ann Intern Med. 2013 Aug;159(4):253-61.

17. Fleischmann R, Kremer J, Cush J, Schulze-Koops H, Connell C a, Bradley JD, et al. Placebo-controlled trial of tofacitinib monotherapy in rheumatoid arthritis. N Engl J Med [Internet]. 2012 Aug 9 [cited 2014 Oct 15];367(6):495-507. Available from: http://www.ncbi.nlm.nih.gov/pubmed/22873530

18. Lee EB, Fleischmann R, Hall S, Wilkinson B, Bradley JD, Gruben D, et al. Tofacitinib versus methotrexate in rheumatoid arthritis. N Engl J Med. 2014 Jun;370(25):2377-86.

19. Wollenhaupt J, Silverfield J, Lee EB, Curtis JR, Wood SP, Soma K, et al. Safety and efficacy of tofacitinib, an oral janus kinase inhibitor, for the treatment of rheumatoid arthritis in open-label, longterm extension studies. J Rheumatol. 2014 May;41(5):837-52.

20. Schneeberger E, Salas A, Medina LF, Al. E. Real-world use of tofacitinib in rheumatoid arthritis: data from Latin America. In: Poster presented at the 20th Pan-American Congress of Rheumatology. Buenos Aires, Argentina.; 2018.

21. Strand V, Mysler E, Moots RJ, Wallenstein G V, DeMasi R, Gruben D, et al. Patient-reported outcomes for tofacitinib with and without methotrexate, or adalimumab with methotrexate, in rheumatoid arthritis: a phase IIIB/IV trial. RMD Open. 2019 Oct 1;5(2):e001040. 
22. Qorolli M, Rexhepi B, Rexhepi S, Mustapić M, Doko I, Grazio S. Association between disease activity measured by RAPID3 and health-related quality of life in patients with rheumatoid arthritis. Rheumatol Int. 2019 May 7;39(5):827-34.

23. Kim S-K, Park S-H, Bae J, Son JT, Choe J-Y. Performance of Routine Assessment of Patient Index Data 3 (RAPID3) for assessment of rheumatoid arthritis in clinical practice: differential agreement of RAPID3 according to disease activity categories. Rheumatol Int. 2014 Sep 15;34(9):1311-8.

24. Pincus T, Furer V, Keystone E, Yazici Y, Bergman MJ, Luijtens K. RAPID3 (Routine Assessment of Patient Index Data 3) severity categories and response criteria: Similar results to DAS28 (Disease Activity Score) and CDAI (Clinical Disease Activity Index) in the RAPID 1 (Rheumatoid Arthritis Prevention of Structural Damag. Arthritis Care Res (Hoboken). 2011 Aug;63(8):1142-9.

25. Benham H, Rutherford M, Kirby S, Stebbings S, White D, Sim D, et al. Treat-to-target in rheumatoid arthritis: Evaluating the patient perspective using the Patient Opinion Real-Time Anonymous Liaison system: The RA T2T PORTAL study. Int J Rheum Dis. 2019 May 22;22(5):874-9.

26. Pfizer. Pfizer Shares Co-Primary Endpoint Results from Post-Marketing Required Safety Study of XELJANZ $®$ (tofacitinib) in Subjects with Rheumatoid Arthritis (RA) [Internet]. 2021 [cited 2021 May 30]. Available from: https://www.pfizer.com/news/press-release/press-release-detail/pfizer-sharesco-primary-endpoint-results-post-marketing

27. Mease P, Schoeman $C$, Cohen $S$, et al. Incidence of venous and arterial thromboembolic events reported in the tofacitinib rheumatoid arthritis, psoriasis and psoriatic arthritis development programmes and from real-world data. Ann Rheum Dis 2020 Nov;79(11):1400-1413.

28. Curtis JR, Xie F, Yun H, Bernatsky S, Winthrop KL. Real-world comparative risks of herpes virus infections in tofacitinib and biologic-treated patients with rheumatoid arthritis. Ann Rheum Dis [Internet]. 2016 Oct;75(10):1843-7. Available from:

https://ard.bmj.com/lookup/doi/10.1136/annrheumdis-2016-209131

29. Wollenhaupt J, Lee E-B, Curtis JR, Silverfield J, Terry K, Soma K, et al. Safety and efficacy of tofacitinib for up to 9.5 years in the treatment of rheumatoid arthritis: final results of a global, openlabel, long-term extension study. Arthritis Res Ther. 2019 Dec 5;21(1):89.

\section{Figures}




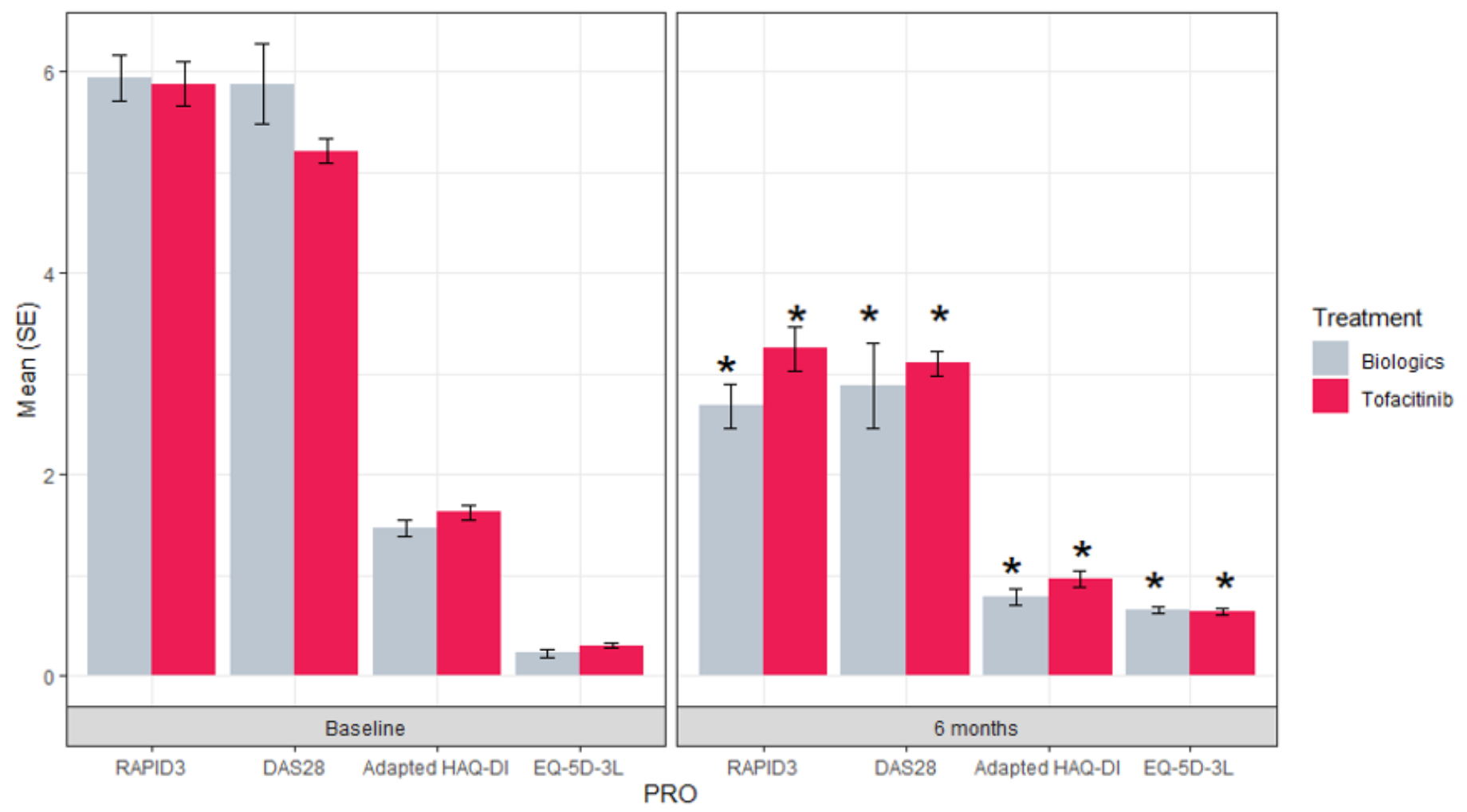

Figure 1. Results of the PROs at baseline and 6 months for each treatment. * p value $<0.001$. bDMARDs: biological disease-modifying anti-rheumatic drugs; DAS28-ESR: Disease Activity Score 28-joint count assessment-erythrocyte sedimentation rate; EQ-5D-3L: EuroQoL 5-Dimension 3-Level; HAQ-DI: Health Assessment Questionnaire - Disability Index; PRO: patient-reported outcomes; RAPID3: Routine Assessment of Patient Index Data 3; SE: standard error.

\section{Figure 1}

See image above for figure legend. 

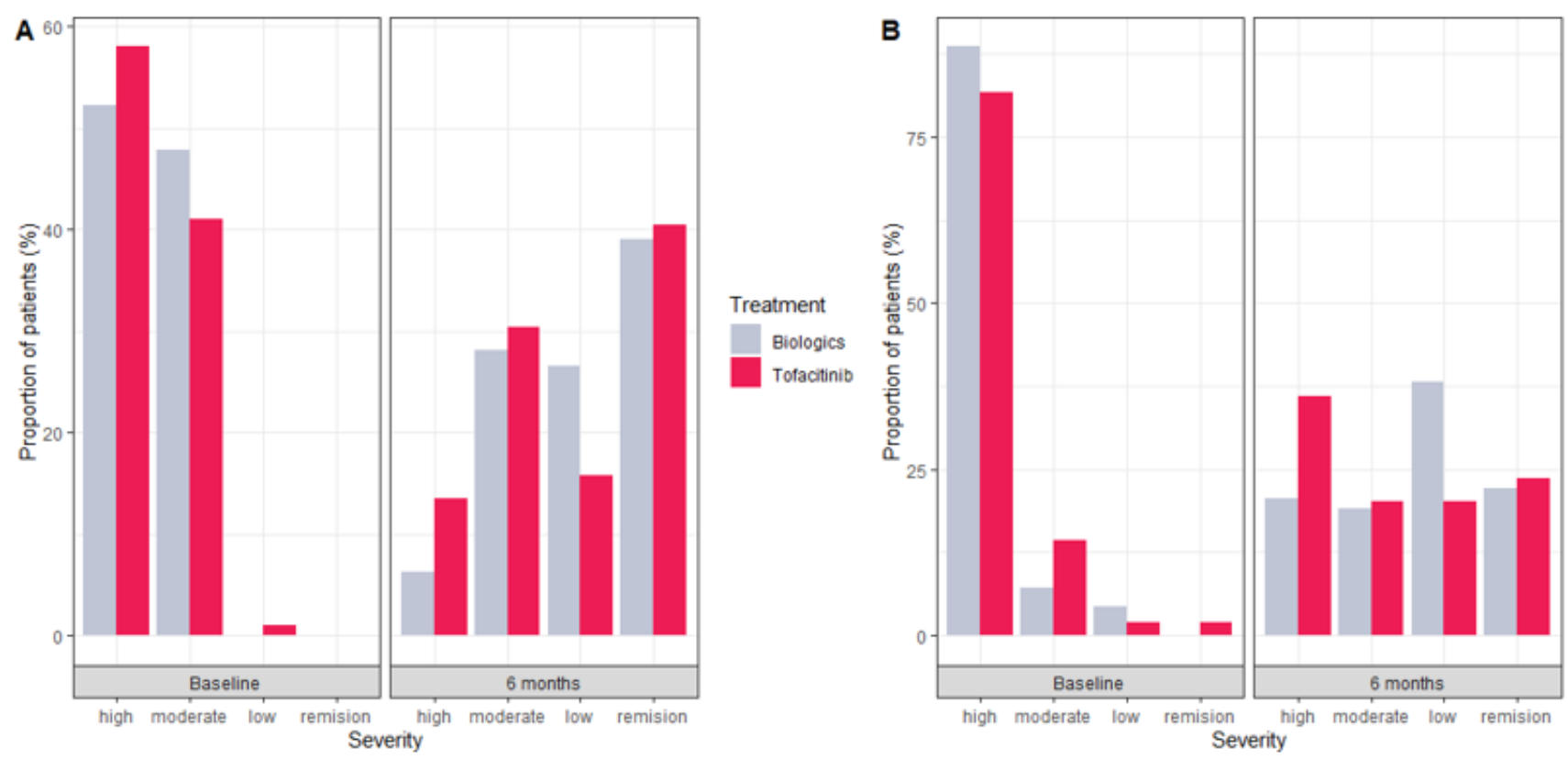

Treatment

Treatment

Biologics

Tofacitinis

Figure 2. Proportion of rheumatoid arthritis patients according to severity at baseline and 6 months. A. Proportion of patients based on DAS28-ESR classification. B Proportion of patients based on RAPID3 severity score.

\section{Figure 2}

See image above for figure legend. 